\title{
Canadians confused and conflicted over sun protection products
}

Published at www.cmaj.ca on July 6

$\mathrm{W}$ hile most Canadians know that sun exposure can cause skin cancer, many are confused over other damage the sun, and potentially sunscreens, can do to their bodies.

A new study by the Canadian Dermatology Association shows that Canadians remain unaware of the true toll the sun can take on their skin and are unwilling to take the full range of precautions necessary to protect themselves from its harmful rays.

Meanwhile, an American report criticizing the industry's use of toxic ingredients and inflated efficacy claims has prompted debate over the safety of Canadian sunscreens.

The 2010 Photoaging Study summary report asserts that 8 in 10 Canadians don't know that the major contributor to skin aging is repeated exposure to sunlight. Photoaging (premature aging of the skin through sun exposure), is the cause of up to $90 \%$ of the skin changes often mistaken as the ravages of time: wrinkles, sagging, liver spots, spider veins, uneven colour and leathery texture. According to the study, two-thirds of Canadians cannot accurately describe what photoaging is; almost a quarter of study participants thought it was a kind of computer software used to give photographs a vintage look (www.derma tology.ca/photoaging/PhotoagingSumm aryReport_May19.pdf).

The study also found that while most Canadians are willing to slap on some sunscreen $(67 \%)$ or slip on a pair of sunglasses $(66 \%)$ to protect themselves from sun damage, fewer were willing to adopt other recommended precautions, like avoiding outdoor tanning $(39 \%)$ or wearing more clothing to cover the skin $(31 \%)$.

But consumer faith in sunscreen may be unwarranted, according to a recent report on the products' safety

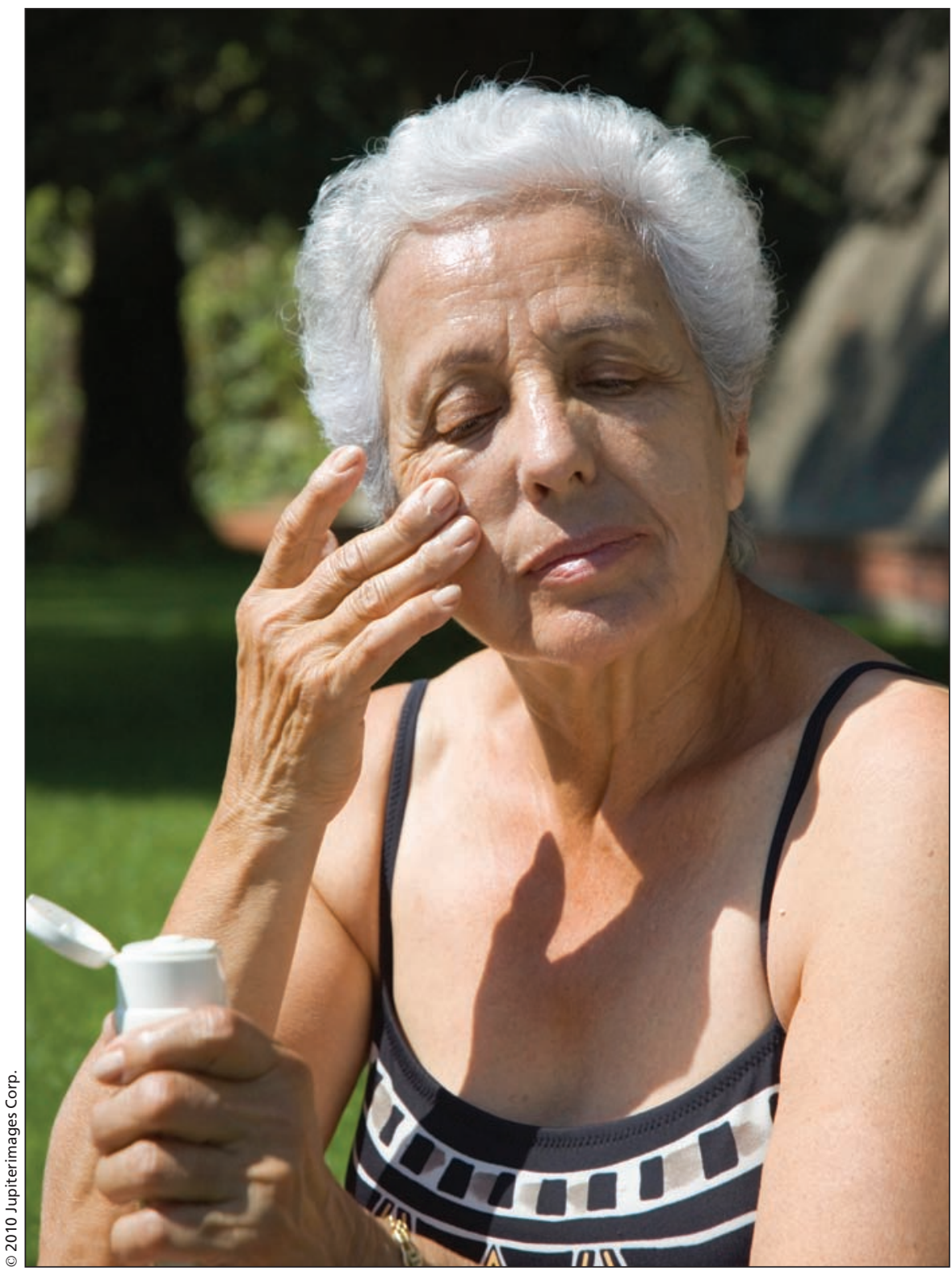

The 2010 Photoaging Study summary report asserts that 8 in 10 Canadians don't know that the major contributor to skin aging is repeated exposure to sunlight.

and efficacy by the Environmental Working Group, a Washington, DCbased nonprofit environmental research and advocacy organization.

In their fourth annual Sunscreen Guide, the group gave low marks to the current crop of sunscreens on the United
States market, recommending only 39 , or $8 \%$, of 500 beach and sport sunscreens as safe for consumer use (www .ewg.org/2010sunscreen/full-report/).

The group cited sunscreens' potentially toxic or unstable ingredients, as well as exaggerated and often unsub- 
stantiated sun protection factor (SPF) and broad spectrum protection claims as reasons for the panning.

"Products with high SPF ratings sell a false sense of security," says Dave Andrews, senior scientist for the group. "We know people who use these products stay out in the sun longer, so they still get burned, and because most of these products provide a low ratio of UVA [ultraviolet A] to UVB [ultraviolet B] protection, they also end up getting overexposed to UVA radiation, the type of sunlight that doesn't burn but has been linked to skin damage and cancer."

Common sunscreen ingredients like oxybenzone, used as a UVA/UVB absorber, and a form of vitamin A called retinyl palmitate, hawked for its anti-aging benefits, also came under fire for potential toxicity and photoinstability.

"Oxybenzone is a known hormonedisrupting compound found in about $60 \%$ of the sunscreens we looked at, and retinyl palmitate, found in about $40 \%$ of the sunscreens, is under investigation by the federal Food and Drug Administration [FDA] because data suggests it may become carcinogenic in sunlight," Andrews explains. "While the evidence isn't conclusive, as long as compounds like these are suspect, it's only prudential to avoid them."

The group's report is the latest in a recent spate of studies that have questioned the safety of sunscreens. Some have even linked sunscreen use to an elevated risk for melanoma, the deadliest form of skin cancer, says Andrews.

The Environmental Working Group's report has divided Canadian experts over what dangers, if any, lurk on sunscreen shelves.

Dr. Barry Lycka, founder of the Canadian Skin Cancer Foundation, is quick to dismiss the report as "erroneous" and "misleading." He argues that it is "hazardous" at best to adapt an
American study to a Canadian context. "We have totally different products in Canada. We're much more cautious than other countries in endorsing anything, and when people make claims they pretty well have to live by them. I would be much more positive and look for things that are good in sunscreens, rather than look for things that are bad."

Lycka says that while it's "probably true" that only $8 \%$ of sunscreens protect against UVA radiation, UVB protection is the "major component" Canadians should be looking for in a sunscreen.

Others dismiss the group's concern over the use of oxybenzone in sunscreens.

"There have been animal studies that show there might be endocrine effects, but there's nothing conclusive in human studies," says Dr. Cheryl Rosen, national director of the Canadian Dermatology Association's sun awareness program. "It's something we should watch the literature on, but that doesn't mean we have to stop using these products now. Oxybenzone has been used in sunscreen for years, and as far as I know there haven't been reported problems in humans."

But environmentalists are disappointed by the ready dismissal of the report and say there's no reason for industry to use hormonally-active ingredients when safer alternatives are available.

"There are something like 80000 synthetic chemicals in commerce at the moment. Only $5 \%$ of those have been adequately safety tested, and oxybenzone is not one of them," says Rick Smith, executive director of Environmental Defence Canada, an environmental and human health advocacy group. "It's glib to tell consumers not to worry about oxybenzone because it's been deemed safe by the government regulator, because once upon a time tobacco was deemed safe, too."
As regulated drugs in Canada, sunscreens are required to undergo premarket authorization to demonstrate safety and efficacy. Most meet the criteria for acceptable active ingredients, permitted concentrations, directions for use, and required warning statements outlined in the 1995 Sunburn Protectant monograph. Oxybenzone is currently among the ingredients generally recognized as safe by Health Canada.

Under the monograph, sunscreens can have an SPF rating no higher than 60 and can only make limited UVA protection claims. But sunscreens don't have to meet the monograph criteria, as manufacturers can present additional evidence to Health Canada to bring sunscreens with higher SPFs, new ingredients and different claims to market.

Smith says many sunscreens approved by Health Canada wouldn't pass muster under the Environmental Working Group's criteria. "Virtually all the brands the group looked at are also available here in Canada. We use the same ingredients in our sunscreens, the average SPF rating is still climbing, albeit at a slower pace than in the US, and there's still no consensus on how best to test for UVA protection. Superficially, it may seem we're ahead of the game, but the same problems with sunscreen you see in the US apply here in Canada."

The FDA has yet to finalize regulations for sunscreens promised since 1978 , but says regulations may be issued in October. Health Canada last updated its monograph in 2006, and says it is "exploring methods by which to better communicate to Canadians the importance and level of UVA protection on sunscreens, as well as which UVA protection-test methods are the most appropriate for use." - Lauren Vogel, CMAJ

DOI:10.1503/cmaj.109-3309 